\title{
Direct Impact of T Cells on Neurons Revealed by Two- Photon Microscopy in Living Brain Tissue
}

\author{
Robert Nitsch, ${ }^{1 \star}$ Elena E. Pohl, ${ }^{1 \star}$ Alina Smorodchenko, ${ }^{2}$ Carmen Infante-Duarte, ${ }^{2}$ Orhan Aktas, ${ }^{2}$ and Frauke Zipp ${ }^{2}$ \\ Institutes of ${ }^{1}$ Anatomy, Department of Cell and Neurobiology, and ${ }^{2}$ Neuroimmunology, Humboldt University Medical School Charité, D-10098 Berlin, \\ Germany
}

\begin{abstract}
Encephalitogenic T cells invade the brain during neuroinflammation such as multiple sclerosis (MS), inducing damage to myelin sheaths and oligodendrocytes. Only recently, neuronal structures were reported to be a crucial target in the disease. Here, two-photon microscopy using ion-sensitive dyes revealed that within the complex cellular network of living brain tissue, proteolipid protein (PLP)-specific T cells and T cells recognizing the nonmurine antigen ovalbumin (OVA) directly and independently of the major histocompatibility complex (MHC) contact neurons in which they induce calcium oscillations. T cell contact finally resulted in a lethal increase in neuronal calcium levels. This could be prevented by blocking both perforin and glutamate receptors. For the first time, our data provide direct insight into the activity of $\mathrm{T}$ cells in the living brain and their detrimental impact on neurons.
\end{abstract}

Key words: multiple sclerosis; neuronal cell death; neuroinflammation; calcium; glutamate; brain tissue; perforin

\section{Introduction}

The trafficking of encephalitogenic T cells through the brain is regarded as the primary pathogenic event in neuroinflammatory diseases such as multiple sclerosis (Martin et al., 1992; Martino and Hartung, 1999). T cells encounter their specific antigenic peptide, presented via major histocompatibility complex molecules (MHC), and subsequently attack brain cells. Damage to myelin sheaths and the myelin-forming cell, the oligodendrocyte, has been the main focus of research in autoimmune neuroinflammation (Selmaj and Raine, 1988; Raine, 1997). Recent findings, however, indicate that damage to axons and their parent cell bodies (Ferguson et al., 1997; Trapp et al., 1998; Smith et al., 2000; Meyer et al., 2001; Peterson et al., 2001; Diestel et al., 2003) must now also be considered an important but underestimated pathological event that intriguingly correlates with the clinical course of MS (Coles et al., 1999; Bjartmar et al., 2000). The current and still limited view on the interaction between $\mathrm{T}$ cells and neuronal structures is based on data obtained from histopathological or immunocytochemical studies in postmortem brain tissue or cocultures of T cells with dissociated single-cell cultures (D'Souza et al., 1995; Malipiero et al., 1999; Medana et al., 2000).

However, the critical issue of the dynamics, sequence, and functional relevance of a direct interaction between $\mathrm{T}$ cells and neurons in the course of $\mathrm{T}$ cell trafficking through the complex

\footnotetext{
Received 0ct. 17, 2003; revised Jan. 6, 2004; accepted Jan. 12, 2004.

This study was supported by the Deutsche Forschungsgemeinschaft: SFB 507, the Bundesministerium für Bildung und Forschung (R.N., F.Z.), and the Gemeinnützige Hertie Stiftung/Institute for Multiple Sclerosis Research, University Goettingen (F.Z.). We thank Nancy Nowakowski for technical assistance and Kimberly Rosegger for editorial assistance. O.A. and F.Z. contributed as senior authors to this work.

${ }^{*}$ R.N. and E.E.P. contributed equally to this work.

Correspondence should be addressed to Dr. Frauke Zipp, Institute of Neuroimmunology, Medical School Charité, D-10098 Berlin, Germany. E-mail: frauke.zipp@charite.de.

DOI:10.1523/JNEUROSCI.4703-03.2004

Copyright $\odot 2004$ Society for Neuroscience $\quad 0270-6474 / 04 / 242458-07 \$ 15.00 / 0$
}

cellular network of living brain parenchyma can only be addressed in an organ culture approach. To that end, we have used two-photon microscopy on living brain slices which, in contrast to dissociated cell cultures, maintain the characteristic organization of all cellular components of the brain (Misgeld and Frotscher, 1982; Hailer et al., 1996; Gahwiler et al., 1997). Fluorescence-dye-prelabeled T cells were allowed to invade the brain parenchyma and ion-sensitive dyes revealed the functional consequences thereof. In an earlier study, we were already able to show that $\mathrm{T}$ cells applied to brain slices could be detected within the parenchyma of that living brain tissue (Gimsa et al., 2000).

\section{Materials and Methods}

\section{Animals and brain slices}

All animals were housed under standard laboratory conditions, and the surgical procedures were performed in agreement with the German law (in congruence with $86 / 609 / \mathrm{EEC}$ ) on the use of laboratory animals. Briefly, 10-d-old SJL/J $\left(\mathrm{H}-2^{\mathrm{s}}\right)$ or B10.PL $\left(\mathrm{H}-2^{\mathrm{u}}\right)$ mice were decapitated, brains were removed quickly, and $400-\mu \mathrm{m}$-thick slices were cut with a Vibratome (NVSLM1; Motorized Advance Vibroslice). Slices were transferred to a thermoregulated recording chamber, which was continuously perfused with aerated $\left(95 \% \mathrm{O}_{2}, 5 \% \mathrm{CO}_{2}\right)$ artificial CSF (ACSF) containing (in mM): $\mathrm{NaCl}, 124 ; \mathrm{NaH}_{2} \mathrm{PO}_{4}, 1.25 ; \mathrm{NaHCO}_{3}, 26 ; \mathrm{KCl}, 3 ; \mathrm{CaCl}_{2}, 1.6$; $\mathrm{MgSO}_{4}, 1.8$ and glucose, $10, \mathrm{pH} 7.35$. Acute slices were allowed to recover for at least $1 \mathrm{hr}$ at room temperature. Thirty minutes before imaging, slices were loaded with cell-permeable $\mathrm{Ca}^{2+}$-indicator Fluo-4 (10 $\mu \mathrm{M}$; Molecular Probes, Eugene, OR). For this study 96 acute brain slices from 42 mice were investigated. Slices showing an elevated $\mathrm{Ca}^{2+}$ cell content after incubation with Fluo-4 (four slices) were rejected as artifacts before experiment. Blockade of glutamate receptors was achieved using MK801, AP-5, and NBQX (all from Sigma, Deisenhofen, Germany) added in final concentrations of $10,50,10 \mu \mathrm{M}$, respectively. The stimulation of glutamate receptors was performed with $10 \mu \mathrm{M}$ L-glutamate (Sigma). Neuronal cell death was assessed by incubation with propidium iodide (Sigma) before fixation as previously described (Gimsa et al., 2000). 
Generation and characterization of encephalitogenic T cells

$\mathrm{T}$ cell lines recognizing the proteolipid protein (PLP) epitope $139-151$ or the non-murine protein ovalbumin (OVA) were established in SJL/J mice (Charles-River, Sulzfeld, Germany) as previously described (Brocke et al., 1996). In brief, female SJL/J mice (6-8 weeks; Charles-River) were immunized with PLP 139-151 (purity $>95 \%$; Pepceuticals, Leicester, UK) or OVA (Sigma, Taufkirchen, Germany), and draining lymph node cells were isolated $10 \mathrm{~d}$ later. Cells were stimulated with PLP139-151 (10 $\mu \mathrm{g} / \mathrm{ml}$ ) or OVA for $4 \mathrm{~d}$ in cell culture medium (RPMI 1640 supplemented with $2 \mathrm{~mm}$ L-glutamine, $100 \mathrm{U} / \mathrm{ml}$ penicillin, $100 \mu \mathrm{g} / \mathrm{ml}$ streptomycin, and $10 \%$ fetal calf serum), and thereafter washed and kept in cell culture medium supplemented with rhIL-2. This resulted in CD4+CD8CD25+CD69+CD44+ Th-1-like $\mathrm{T}$ cell lines releasing IFN- $\gamma$ and TNF- $\alpha$, but almost no IL-4. The T cells were kept at a concentration of $1-2 \times 10^{6}$ cells $/ \mathrm{ml}$ and restimulated every $14 \mathrm{~d}$ using $5-10 \mu \mathrm{g} / \mathrm{ml}$ antigen presented on irradiated (3000 rad) syngeneic spleen cells at a ratio of $1 / 2-1 / 3$ T cells versus antigen-presenting cells (APC). Antigen specificity was routinely checked by standard ${ }^{3}[\mathrm{H}]$-thymidine incorporation assays, indicating a specific stimulation index $>10$. FACS analysis was performed for CD4 (all antibodies from BD Bioscience, San Jose, CA) and CD8, activation markers CD25 and CD69, and for the memory

\section{Immunization of SJL- mice with PLP or OVA}

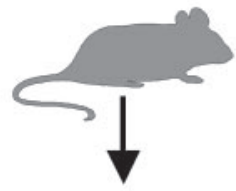

Generation of $\mathrm{T}$ cell lines

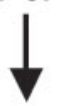

Labelling with CMTMR for 30 minutes (rhodamine cell tracker)

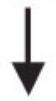

Application to slice 1 hour prior to analysis

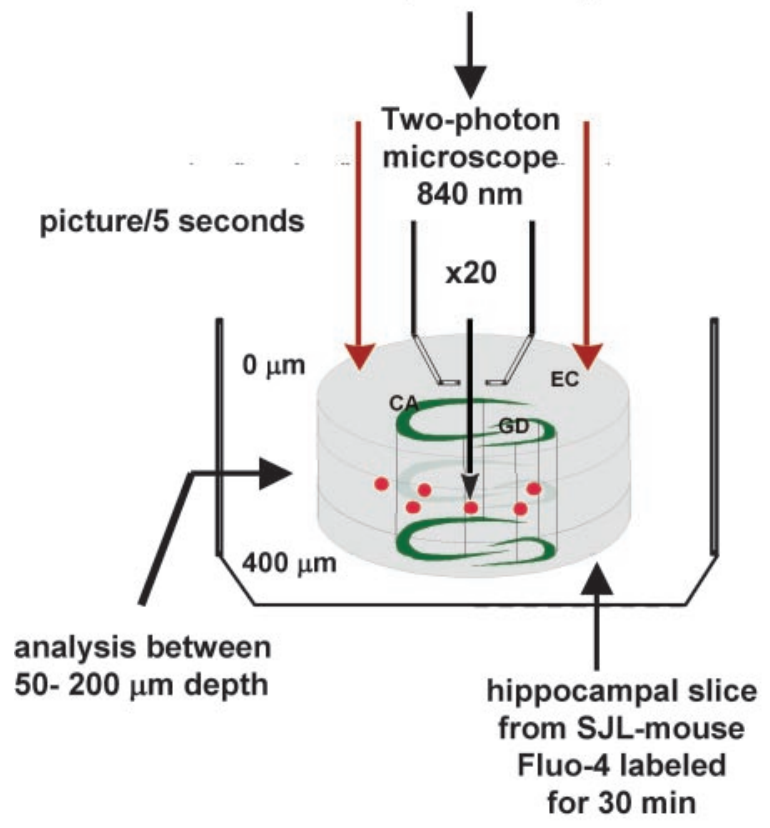

Figure 1. Experimental set-up.

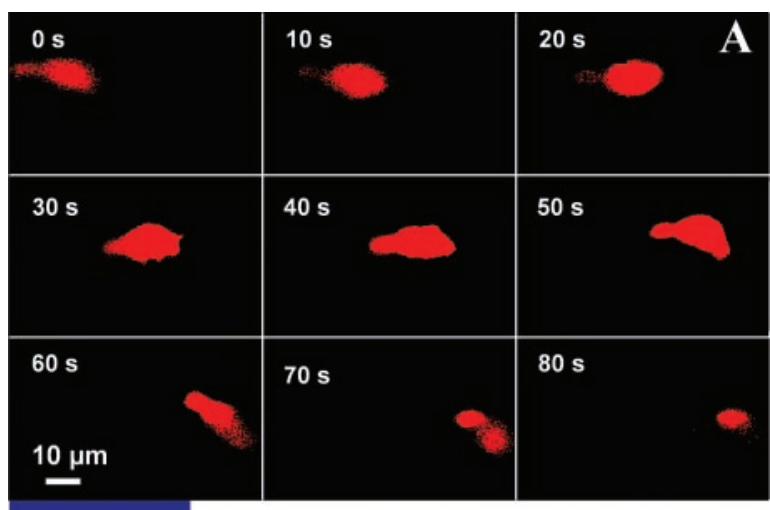

Movie 2A
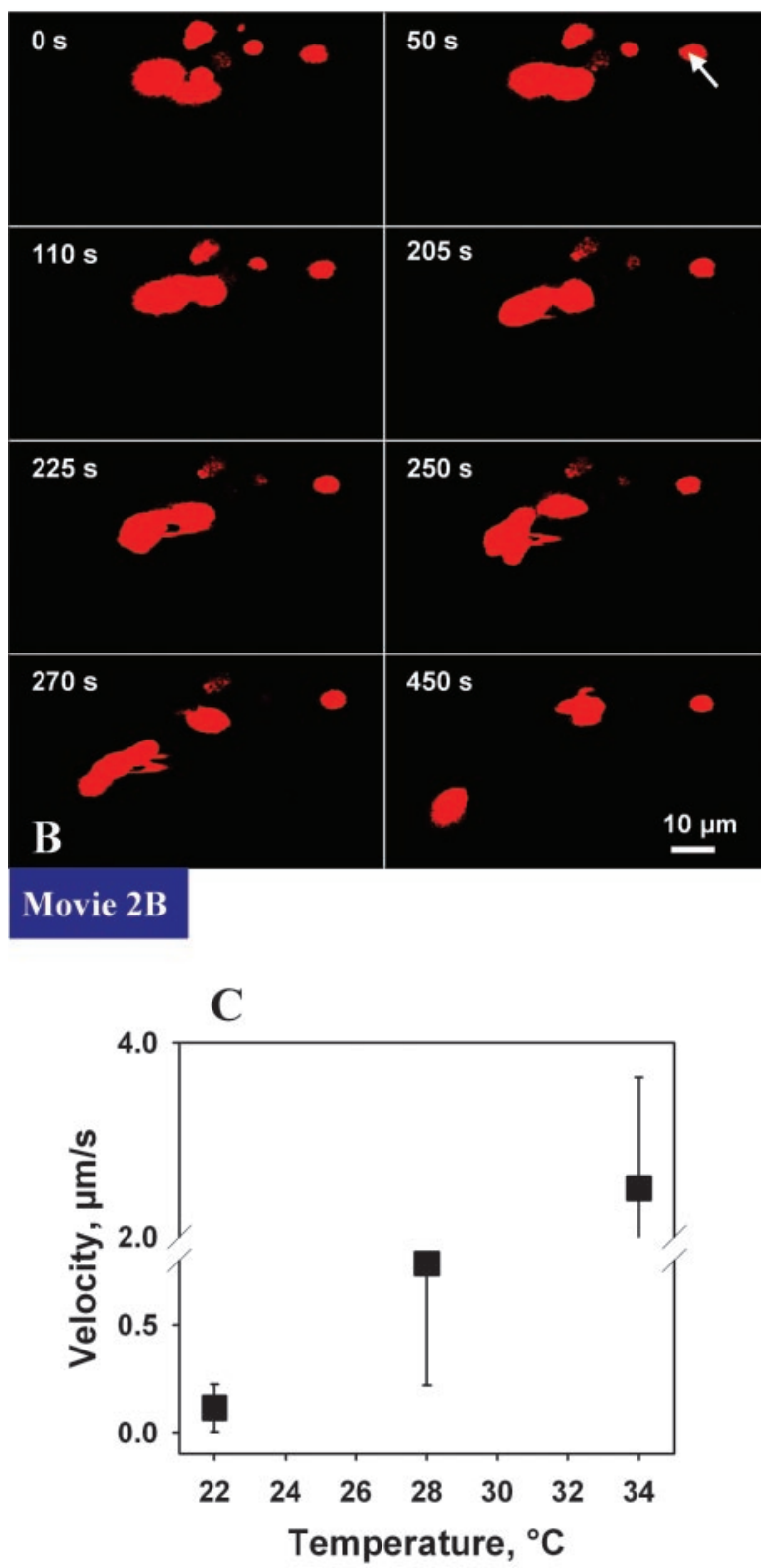

Figure 2. Two-photon imaging of $\mathrm{T}$ cell morphology and trafficking through living brain tissue. Lymphocytes are stained with CMTMR (red). Only red channel is shown (compare Fig. 3). $A$, Torpedo-like movement of $\mathrm{T}$ cells within living brain tissue at visualization depth of $70 \mu \mathrm{m}$. $B$, Transient contact of $T$ cells with each other when trafficking through living brain tissue. The stationary cells mostly have a round shape (arrow). C, Diagram of average cell velocity at different incubation temperatures. 
status CD44. Intracellular analysis was performed for IFN- $\gamma$, TNF- $\alpha$, and IL-4 after activation with PMA-ionomycin. Cytotoxicity of these T cells was inhibited using the perforin-blocking agent concanamycin A (CMA) at $200 \mathrm{~nm}$ (Sigma) (Appay et al., 2002).

\section{Two-photon microscopy and data analysis}

T-lymphocytes and neurons in acute slices were visualized by a two-photon set-up (Leica, Heidelberg, Germany) using an upright microscope equipped with a $20 \times$ water-immersion objective (numerical aperture 0.5 ; Leica). Fluorescent dyes [(Fluo-4 and [5-(and 6-)-(((4-choloromethyl) benzoyl) amino) tetramethylrhodamine)] (CMTMR)] were excited simultaneously by a mode-locked Ti-sapphire laser (Tsunami; Spectra-Physics) at wavelength $840 \mathrm{~nm}$. Fluorescence from green (Fluo-4) and red (CMTMR) channels was collected using two external non-descanned detectors. Resulting data from each channel were merged into final two-color images. Three- or four-dimensional ( $x-y$ plane, $t$, or $x-y-z$ plane, $t)$ images $(512 \times 512$ pixels $)$ were acquired from various slice depths $(50-200 \mu \mathrm{m})$ usually every $5 \mathrm{sec}$. Images were analyzed off-line using NIH Image J software (version 1.28, W. Rasband). To quantify $\mathrm{Ca}^{2+}$ changes in neurons, the fluorescence intensity in percentage of maximum was calculated for selected regions of interest (ROI) and for a defined time interval.

Online supplemental material (available at www.jneurosci.org) Movie 2A. Torpedo-like movement of T cells within living brain tissue at a visualization depth of $70 \mu \mathrm{m}$ (see Fig. $2 A$ ). Lymphocytes are stained with CMTMR (red). Only red channel is shown. XYT images (size $64 \times$ $42 \mu \mathrm{m}$; original size $156 \times 156 \mu \mathrm{m}$ ) were acquired at $5 \mathrm{sec}$ intervals. Video shows a $15 \mathrm{sec}$ picture sequence.

Movie 2B. Transient contact of T cells with each other when trafficking through living brain tissue. Lymphocytes are stained with CMTMR (red). Only red channel is shown. XYT images (size $111 \times 68 \mu \mathrm{m}$; original size $156 \times 156 \mu \mathrm{m}$ ) were acquired every $5 \mathrm{sec}$ (picture) and shown in a $10 \mathrm{sec}$ sequence (see Fig. $2 B$ ).

Movie 3A. Glutamate-induced increase of calcium in neurons (without involvement of T cells). Video shows a $10 \mathrm{sec}$ image sequence (see Fig. $3 A$ ).

Movie 3B. Interaction of PLP-specific T cells (red) with hippocampal neurons (green) in living brain tissue. Video shows a $10 \mathrm{sec}$ image sequence (see Fig. $3 B$ ).

Movie 3C. Interaction of PLP-specific T cells (red) with hippocampal neurons (green) in living brain tissue. Video shows a $10 \mathrm{sec}$ image sequence (see Fig. 3C).

Movie $3 H$. Visualization of contacts between T cells (red) and a hippocampal neuron (green) in living brain tissue. Video shows $z$-axis analysis (see Fig. $3 H$ ). Six $x-y$ planes were recorded every $3 \mu \mathrm{m}$ in $z$-direction.

Movie 3I. Interaction of OVA-specific T cells (red) with hippocampal neurons (green) in living brain. Video shows a $10 \mathrm{sec}$ image sequence (see Fig. 3I).

Movie 4A. Interaction of PLP-specific T cells (red) obtained from SJL/J $\left(\mathrm{H}-2^{\mathrm{s}}\right)$ mice with hippocampal neurons (green) in living brain tissue from B10.PL $\left(\mathrm{H}-2^{\mathrm{u}}\right)$ mice. Video shows a $10 \mathrm{sec}$ image sequence (see Fig. $4 A)$.

\section{Results}

In the present study, PLP-specific as well as OVA-specific $\mathrm{T}$ cell lines were generated from SJL mice. Living cortical slices were obtained from SJL/J and B10.PL mice at a thickness of $400 \mu \mathrm{m}$ and transferred into a thermoregulated perfusion chamber for investigation with two-photon microscopy (Fig. 1).

In a first set of experiments, the dynamics of $\mathrm{T}$ cell trafficking through the intact brain parenchyma were assessed. For that purpose, $\mathrm{T}$ cells were labeled with red CMTMR fluorescent dye before their invasion into the living brain slice. Lympho- cytes were transferred onto the slice. After 15 min, most of the stimulated $\mathrm{T}$ cells either adhered to the slice surface or had already invaded the brain parenchyma (Gimsa et al., 2000). This was not the case for unstimulated $\mathrm{T}$ cells, which were almost never detected within the parenchyma of the brain slice (data not shown). For a time period of up to $3 \mathrm{hr}$ after invasion, cells were continuously (usually every $5 \mathrm{sec}$ ) scanned using a Leica two-photon microscope (Fig. 1). T cell movement could be followed from the surface of the slice deep into the intermediate layer of the tissue, where a well preserved organization of the complex network of the brain parenchyma containing all cellular structures has been demonstrated (Misgeld and Frotscher, 1982). On the surface of the slice, $\mathrm{T}$ cells were numerous and formed large clusters from which single cells began to break out (data not shown). T cells were primarily monitored within the preserved intermediate layer of the slice at a depth of 50-200 $\mu \mathrm{m}$ (Fig. 1). There, lymphocytes were found in both stationary and moving states, in the latter instance showing an ovoid or peanut-like shape (Fig. $2 \mathrm{~A}$; movie $2 \mathrm{~A}$ ). Stationary T cells were mostly round (Fig. $2 B$, arrow) and often found in clusters showing search-like behavior (Fig. $2 B$; movie 2B). Cells leaving clusters initiated their movement as if they were trying to escape, indicated by an amoeboid extrusion of their peripheral cell surface (Fig. $2 \mathrm{~B}$; movie $2 \mathrm{~B}$ ). Moving cells followed straight paths in a given direction by elongating their body in an "hourglass" manner. Frequently, they stopped suddenly and took a path in the opposite direction (movie $2 \mathrm{~A}$ ). Moving cells regularly bypassed other stationary or also moving cells in the course of their passage. The velocity of lymphocyte movements depended considerably on slice temperature (Fig. $2 C$ ). Experiments were performed at 22,28 , and $34^{\circ} \mathrm{C}$ and showed a corresponding increase in velocity from $0.1 \mu \mathrm{m} / \mathrm{sec}$ up to $2.5 \mu \mathrm{m} /$ $\mathrm{sec}$, as well as a significant increase in inter-T cell variability.

So far, T cell-neuronal interaction has only been studied in coculture assays of $\mathrm{T}$ cells with dissociated single neurons in which all other cellular components of brain tissue are absent (D’Souza et al., 1995; Malipiero et al., 1999; Medana et al., 2000). In contrast, we have here taken advantage of a strategy allowing the analysis of the complex network of living brain tissue ex vivo (Gahwiler et al., 1997; Gimsa et al., 2000). To assess the functional impact of T cell-neuronal interaction in the brain environment, slices were incubated with Fluo-4 (Gee et al., 2000; McDonough et al., 2000) for $30 \mathrm{~min}$ and washed before the invasion of T cells (Fig. 1). In the absence of T cell contact, neuronal cell bodies and their dendritic processes located in the intact intermediate cellular layers CA1 and CA3 of the hippocampus (Fig. 1) contained

Figure 3. Interaction of T cells (red) with hippocampal neurons (green) in living brain tissue. $A$, In control experiments where no $T$ cells were present, glutamate induced a transient increase in neuronal calcium concentration. $B, T$ cell-induced transient increase in neuronal calcium concentration via contact with neuronal cell body (1) or dendrite (2). C, Oscillation of fluorescence intensity indicating calcium levels in neurons $(1,2)$ within the hippocampal neuronal cell layer induced by contact with PLPspecific T cells. After prolonged contact with a lymphocyte (red), the calcium level as indicated by Fluo-4 labeling remained high (3), indicating maximal activation of neuron with subsequent cell death. Note that only a low Fluo-4 signal is apparent in neurons located in the typical hippocampal cell layer which are devoid of T cell contact, indicating normal calcium levels. D, Increase in fluorescence intensity over time in neuron 2 in C.E, Typical time lapse of fluorescence increase in a neuron that has been contacted by a T cell. After the initial occurrence of calcium transients, which were accompanied by a continuous increase in the basic calcium level in the cell cytoplasm, a persisting and stable maximal calcium level was achieved. $F$, Propidium iodide labeling of dead nuclei (color-coded blue) after the invasion of $\mathrm{T}$ cells and subsequent increase in neuronal calcium concentrations confirmed cell death. $G$, Quantitative assessment of T cell-neuronal contacts and effects on $\mathrm{Ca}^{2+}$ levels in neurons. $H$, Three-dimensional image obtained from an $x-y-z$ recording of a Fluo-4-positive neuron (see arrow 1) and its vicinity demonstrates that in the case of neuronal activation without primarily visible cell-cell interaction, an obligatory contact (see arrow 3) of this neuron with lymphocytes (see arrow 2) can be found in other confocal layers (movie 3H). The plot was reconstructed from six $x-y$ planes with a 3 $\mu \mathrm{m}$ interval along the $z$-direction. The total depth monitored was $15 \mu \mathrm{m}$. I, Oscillation of neurons within the hippocampal neuronal cell layer induced by contact with OVA-specific T cells. Note that neurons that are located in the typical hippocampal cell layer and are devoid of T cell contact show only a low Fluo-4 signal, indicating normal calcium levels. 

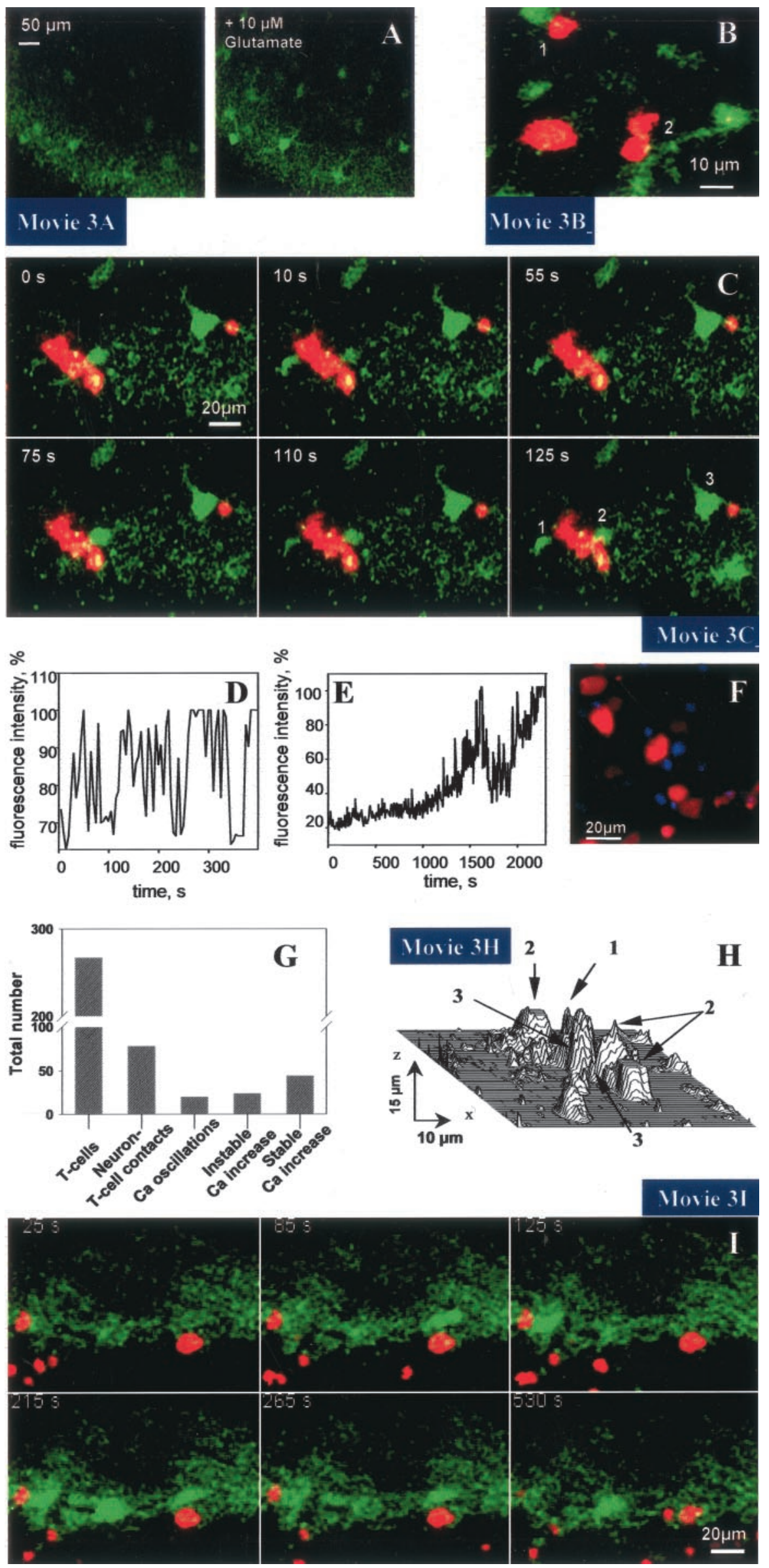

calcium at physiological levels, as revealed by the low fluorescence of the calciumsensitive dye (Fig. $3 A$, left, I). As a positive control, the addition of $10 \mu \mathrm{M}$ glutamate led to a transient increase of the Casensitive dye (Fig. $3 A$, right; movie $3 \mathrm{~A}$ ).

After invasion into the neuronal cell layers of the hippocampus, CMTMRlabeled PLP-specific T cells were seen in the close vicinity of neuronal structures (Fig. 3B; movie 3B). Some of these T cells got into direct contact with neuronal cell bodies and processes, in most cases the proximal portions of dendrites (Fig. $3 B$; movie 3B). In the case of sustained contact with a neuron, an induction of oscillatory changes in intracellular neuronal calcium concentration could be observed (Fig. 3C; movie 3C). We assessed a total of $267 \mathrm{~T}$ cells and detected $75 \mathrm{~T}$ cell-neuronal contacts (Fig. 3G). The contact between more than one lymphocyte and one neuron was regarded as one contact. $\mathrm{T}$ cell contacts with neuronal cell bodies as well as with dendrites at a distance up to $40 \mu \mathrm{m}$ from the soma were included.

Twenty individual neurons were monitored before and during the entire period of direct contact with a PLP-specific T cell. In this way, we were able to follow changes from the early stage of oscillations to the final increase in fluorescence (Fig. 3, compare $D, E)$. Calcium concentrations in neurons as indicated by neuronal Fluo- 4 staining showed oscillatory changes enforced by $\mathrm{T}$ cell contact (Fig. 3C; movie 3C). These calcium oscillations, observed on a time scale in the minute range, showed a frequency of $0.04 \pm 0.01 \mathrm{~Hz}$ (calculated from 20 neurons) and a rise in amplitude up to $80 \%$ (Fig. $3 D$ ). In some cases only a single oscillation (20 neurons) or a weak calcium increase (24 neurons) was detected (Fig. $3 G$ ). Over time, a rise in intracellular calcium was observed in neurons with $\mathrm{T}$ cell contact, which finally resulted in a stable dye signal (Fig. 3D,E). As assessed by evaluating the Fluo- 4 fluorescence intensity changes in neurons from $x-y-t$ records of brain slices, $58.7 \%$ of all contacts led to a stable calcium increase (Fig. $3 G$ ). This was derived from final overview pictures made at the end of each experiment (usually after at least $3 \mathrm{hr}$ ). Fluorescence intensity was comparable to that seen in neurons at the surface of the brain slice, an area of tissue severely damaged by the preparation procedure (Misgeld and Frotscher, 1982). Quantitative assessment based on the high affinity of the Fluo-4 to calcium revealed calcium levels in damaged neurons above $1 \mu \mathrm{m}$. Although such a stable calcium overload in neurons is indicative of cell death (Choi, 1995; Nicotera and 

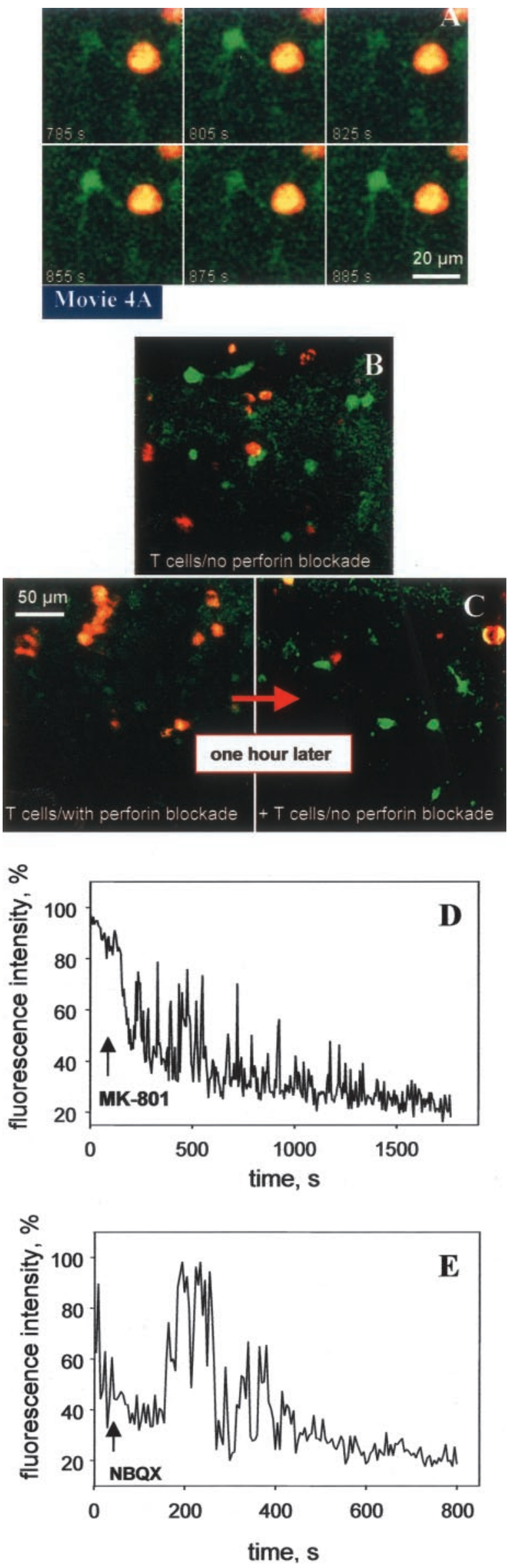

Orrenius, 1998; Yu et al., 2001), additional experiments were performed to show that neurons adjacent to T cells were dead. Brain slices were stained with the cell death marker propidium iodide (PI) after invasion of encephalitogenic T cells (stained with CFDA), highlighting nuclei (color-coded blue) of dead neurons next to T lymphocytes (Fig. $3 F$ ). Importantly, three-dimensional analysis using $z$-axis measurements confirmed that all neurons showing an irreversible increase in calcium levels were in contact with a T cell (Fig. $3 \mathrm{H}$; movie $3 \mathrm{H}$ ). Furthermore, neurons in control slices not cocultured with $\mathrm{T}$ cells did not exhibit oscillations or a rise in calcium concentration (Fig. 3A, left).

We further assessed whether induction of calcium oscillations in neurons could also be achieved in an antigen-independent manner. OVA-specific T cells were also seen in the close vicinity of neuronal structures (Fig. 3I; movie 3I). As observed for PLP-specific T cells, in the case of sustained contact with a neuron, a primarily transient increase in intracellular neuronal calcium could be observed (Fig. 3I; movie 3I). T cell contact enforced oscillatory changes of calcium concentrations in the neurons, of which 20 individual cells were monitored during the period of direct contact with an OVA-specific T cell (Fig. 3I; movie 3I). These calcium oscillations showed kinetics similar to those observed in contact between PLP-specific T cells and neurons. To investigate a dependence of the observed T cellneuronal interactions on the MHC, we applied the CD4+ PLPspecific T cells derived from SJL/J mice expressing an $\mathrm{H}-2^{\mathrm{s}} \mathrm{MHC}$ haplotype onto brain slices derived from B10.PL mice with an $\mathrm{H}-2^{\mathrm{u}}$ MHC haplotype. In this MHC mismatch experiment, we also found neuronal calcium oscillations when T cells and neurons were seen in contact with each other (Fig. $4 A$; movie $4 \mathrm{~A}$ ).

Prevention of the calcium overload was achieved by blockade of perforin-mediated cytotoxicity of PLP-specific T cells with concanamycin-A (Appay et al., 2002) (Fig. 4B,C). Wash-in experiments, in which the glutamatergic neuronal connectivity in the hippocampus was inhibited using blockers of the different glutamate receptors, further reversed the T cell-induced calcium oscillations and, most importantly, prevented the final and stable increase of calcium. Inhibition of NMDA receptors by MK-801 (Fig. 4D) and AP-5 (data not shown), and of AMPA-kainate receptors by NBQX (Choi, 1995) (Fig. 4E), was effective in protecting neurons from $\mathrm{T}$ cell-induced calcium oscillations within a time scale of $500-1000 \mathrm{sec}$, and reduced the calcium load by $80 \%$.

\section{Discussion}

Here, we present the first analysis of the dynamics of $\mathrm{T}$ cells performing their effector function within the complex cellular network of a target organ which is normally devoid of this immune compartment, the brain. Until now, only interactions within the immune system between antigen-presenting cells (APC) and T/B cells occurring in the lymphoid tissue have been

\footnotetext{
$\leftarrow$

Figure 4. Inhibitory effect of perforin blockade and glutamate receptor antagonists on neuronal calcium levels (green) in the presence of encephalitogenic T cells (red). A, Oscillation of neurons within the hippocampal neuronal cell layer (slices obtained from B10.PL (H-2 ${ }^{4}$ )-mice) induced by contact with PLP-specific T cells (cells obtained from SJL/J (H-2 ${ }^{5}$ )-mice). $B$, Invasion of control T cells (without blockade of perforin by concanamycin-A) resulted in permanent neuronal calcium increase. C, Invasion of T cells treated with concanamycin-A, which inhibits perforin release, did not induce detectable calcium increase in neurons. One hour later, additional control $\mathrm{T}$ cells (without blockade of perforin by concanamycin-A) were allowed to invade, which induced calcium increase in neurons as observed in $B . D, E$, Example of decrease in fluorescence intensity in a single neuron after addition of MK-801 $(D)$ and NBQX ( $E)$.
} 
studied using modern ex vivo imaging techniques (Bousso et al., 2002; Cahalan et al., 2002; Miller et al., 2002). Our data provide the first demonstration of searching $\mathrm{T}$ cells getting into direct physical contact with the neuronal cell body or its processes in the living brain environment. Most importantly, this interaction could be shown to result in the induction of a persisting calcium overload in neurons, indicative of cell death (Choi, 1995; Nicotera and Orrenius, 1998; Yu et al., 2001). Thus, for the first time, we provide evidence of direct detrimental effects on neurons by $\mathrm{T}$ cells within the parenchyma of living brain tissue.

In the course of a chronic autoimmune reaction such as experimental autoimmune encephalomyelitis (EAE) or MS, activated encephalitogenic CD4 $+\mathrm{T}$ cells are able to invade the brain parenchyma (Flugel et al., 2001), where they perform their detrimental actions on unaffected brain cells. Until today, T cell effects in the brain have been studied in fixed material using histological staining techniques or in in vitro systems of T cell-neuronal cocultures. Only recently, these studies indicated that neuronal cell death occurs as a result of encephalitogenic T cell infiltration in the course of multiple sclerosis (Bjartmar et al., 2000; Peterson et al., 2001) or experimental autoimmune encephalomyelitis (Smith et al., 2000). However, the underlying cellular mechanisms, e.g., the connection between immune cell infiltration and tissue damage in different models of EAE and other neuroinflammatory diseases, are poorly understood. In vitro studies on $\mathrm{T}$ cell-neuronal interaction have so far been based on cocultures lacking all other cellular components of CNS tissue such as glial cells (Medana et al., 2000). Under these conditions, antigenspecific MHC class I-restricted CD8 + T cells are able to induce cell death of neurons infected with the corresponding virus. The two-photon imaging of real-time T cell movement through living brain tissue used in the present work reveals behaviors similar to those observed in the lymph node, where T cells search for APC (Miller et al., 2002). T cell motility changes from a fast-tracking to a stationary condition, in which $\mathrm{T}$ cells form clusters before they swarm out, were also observed in brain slices. This indicates that a search strategy as seen in the lymph node (Miller et al., 2002) also takes place when $\mathrm{T}$ cells transmigrate through the brain parenchyma. During neuroinflammation, it is well established that $\mathrm{T}$ cells directed against the myelin component PLP induce damage to myelin sheaths and oligodendrocytes (Raine, 1997). Our data show that the antigen specificity of invading $\mathrm{T}$ cells does not restrict the damage to the source of the antigen, the oligodendrocyte, but that these $\mathrm{T}$ cells are able to perform damage to neurons as well. This effect appears to be independent of the antigen and of MHC-restricted antigen presentation, because MHC mismatch did not abrogate it and $\mathrm{T}$ cells directed against a nonmurine antigen, OVA, were also able to induce an increase in neuronal calcium. Thus, the $\mathrm{T}$ cell-neuronal interactions observed here might be of general relevance for inflammatory CNS diseases, because they may explain damage to CNS cells not necessarily at the site of T cell clusters. In fact, neuronal apoptotic cell death has been observed in experimental meningitis (Braun et al., 1999). It is conceivable that similar damage mechanisms as found in our study are responsible for this cell death. In contrast, unstimulated T cells did not elicit these effects. As indicated recently in human single-cell cocultures of T cells and neurons and in a delayed-type hypersensitivity (DTH) animal model (Newman et al., 2001; Giuliani et al., 2003), it appears that stimulation of T cells, independent of their target antigen, enables them to induce neuronal cell death via direct cell-cell contact. Our study provides evidence that in intact brain parenchyma containing neurons and glial cells in an organotypic manner, this collateral damage to neurons induced by $\mathrm{T}$ cells can occur if T cells are properly activated.

In single cell cultures, neurons are not properly wired and do not communicate in an in vivo-like manner. This is different in living brain slices, where all components of the brain parenchyma are preserved in a proper network organization ex vivo (Misgeld and Frotscher, 1982; Gahwiler et al., 1997). In fact, our findings on glutamate receptor blockade indicate that the activity of the neuronal network is critical for the ability of $\mathrm{T}$ cells to induce calcium oscillations and eventually calcium overload in neurons. Our data show that direct inhibition of calcium influx via NMDA receptor blockade or indirect inhibition via blockade of depolarizing AMPA-kainate receptors (Choi, 1995) was able to shelter neurons from $\mathrm{T}$ cell-induced calcium increase. This is in line with the finding that blockade of AMPA receptors is effective in protecting against neuronal cell death (Smith et al., 2000) and results in reduced axonal loss and subsequent amelioration of EAE (Pitt et al., 2000). Because the production of excessive amounts of glutamate by $\mathrm{T}$ cells themselves is currently only hypothesized (Steinman, 2001), it is rather conceivable that the activity of the neuronal network, whether it be directly induced via neuronal interaction or indirectly mediated, is critical for the ability of T cells to induce calcium oscillations and eventually calcium overload in neurons. Moreover, it has been shown in vitro that the neurotoxic effects of the secretory granule protein perforin and the granzymes released by cytotoxic T cells could be prevented by NMDA receptor blockade (Malipiero et al., 1999). Under these conditions, the calcium influx occurs at $\sim 40$ min after exposure to cytotoxic granules, representing a substantial delay (Malipiero et al., 1999). In the present study, we could show that inhibition of perforin release from invading $\mathrm{T}$ cells was as effective in abolishing calcium oscillations and long-term calcium increase as glutamate receptor blockade. This further argues against glutamate release by immune cells as the reason for the beneficial effect of glutamate receptor blockade in EAE. It rather indicates that during $\mathrm{T}$ cell attack, receptor-mediated glutamate toxicity and direct damage by cytotoxic granules are cooperative detrimental events finally leading to calcium overload and cell death (Choi, 1995; Nicotera and Orrenius, 1998; Yu et al., 2001).

Gaining insight into brain tissue which is attacked by $\mathrm{T}$ cells appears to be a timely and important task in the quest for a deeper understanding of the mechanisms involved in the course of neuroinflammation. Two-photon microscopy opens up the opportunity for a novel understanding of $\mathrm{T}$ cell behavior in the brain by directly visualizing cell interaction. Indeed, it has become evident using this approach that in addition to the attack on the myelin sheath as the classical hallmark of multiple sclerosis (Raine, 1997), collateral damage to neurons is induced by T cells as well. These findings support the need for novel therapeutic concepts for protecting neurons from detrimental lymphocyte infiltration of the brain and offer the opportunity to study putative strategies at the level of living cell biology in an organotypic environment.

\section{References}

Appay V, Zaunders JJ, Papagno L, Sutton J, Jaramillo A, Waters A, Easterbrook P, Grey P, Smith D, McMichael AJ, Cooper DA, Rowland-Jones SL, Kelleher AD (2002) Characterization of CD4(+ ) CTLs ex vivo. J Immunol 168:5954-5958.

Bjartmar C, Kidd G, Mork S, Rudick R, Trapp BD (2000) Neurological disability correlates with spinal cord axonal loss and reduced N-acetyl aspartate in chronic multiple sclerosis patients. Ann Neurol 48:893-901.

Bousso P, Bhakta NR, Lewis RS, Robey E (2002) Dynamics of thymocytestromal cell interactions visualized by two-photon microscopy. Science 296:1876-1880. 
Braun JS, Novak R, Herzog KH, Bodner SM, Cleveland JL, Tuomanen EI (1999) Neuroprotection by a caspase inhibitor in acute bacterial meningitis. Nat Med 5:298-302.

Brocke S, Quigley L, McFarland HF, Steinman L (1996) Isolation and characterization of autoreactive T cells in experimental autoimmune encephalomyelitis of the mouse. Methods Enzymol 9:458-462.

Cahalan MD, Parker I, Wei SH, Miller MJ (2002) Two-photon tissue imaging: seeing the immune system in a fresh light. Nat Rev Immunol 2:872-880.

Choi DW (1995) Calcium: still center-stage in hypoxic-ischemic neuronal death. Trends Neurosci 18:58-60.

Coles AJ, Wing MG, Molyneux P, Paolillo A, Davie CM, Hale G, Miller D, Waldmann H, Compston A (1999) Monoclonal antibody treatment exposes three mechanisms underlying the clinical course of multiple sclerosis. Ann Neurol 46:296-304.

D’Souza S, Alinauskas K, McCrea E, Goodyer C, Antel JP (1995) Differential susceptibility of human CNS-derived cell populations to TNF-dependent and independent immune-mediated injury. J Neurosci 15:7293-7300.

Diestel A, Aktas O, Hackel D, Häke I, Meier S, Raine CS, Nitsch R, Zipp F, Ullrich O (2003) Activation of microglial poly(ADP-ribose)-polymerase-1 by cholesterol breakdown products during neuroinflammation: a link between demyelination and neuronal damage. J Exp Med 198:1729-1740.

Ferguson B, Matyszak MK, Esiri MM, Perry VH (1997) Axonal damage in acute multiple sclerosis lesions. Brain 120:393-399.

Flugel A, Berkowicz T, Ritter T, Labeur M, Jenne DE, Li Z, Ellwart JW, Willem M, Lassmann H, Wekerle H (2001) Migratory activity and functional changes of green fluorescent effector cells before and during experimental autoimmune encephalomyelitis. Immunity 14:547-560.

Gahwiler BH, Capogna M, Debanne D, McKinney RA, Thompson SM (1997) Organotypic slice cultures: a technique has come of age. Trends Neurosci 20:471-477.

Gee KR, Brown KA, Chen WN, Bishop-Stewart J, Gray D, Johnson I (2000) Chemical and physiological characterization of fluo-4 $\mathrm{Ca}(2+)$-indicator dyes. Cell Calcium 27:97-106.

Gimsa U, Peter SVA, Lehmann K, Bechmann I, Nitsch R (2000) Axonal damage induced by invading $\mathrm{T}$ cells in organotypic central nervous system tissue in vitro: involvement of microglial cells. Brain Pathol 10:365-377.

Giuliani F, Goodyer CG, Antel JP, Yong VW (2003) Vulnerability of human neurons to T cell-mediated cytotoxicity. J Immunol 171:368-379.

Hailer NP, Jarhult JD, Nitsch R (1996) Resting microglial cells in vitro: analysis of morphology and adhesion molecule expression in organotypic hippocampal slice cultures. Glia 18:319-331.

Malipiero U, Heuss C, Schlapbach R, Tschopp J, Gerber U, Fontana A (1999) Involvement of the $N$-methyl-D-aspartate receptor in neuronal cell death induced by cytotoxic T cell-derived secretory granules. Eur J Immunol 29:3053-3062.

Martin R, McFarland HF, McFarlin DE (1992) Immunological aspects of demyelinating diseases. Annu Rev Immunol 10:153-187.

Martino G, Hartung HP (1999) Immunopathogenesis of multiple sclerosis: the role of T cells. Curr Opin Neurol 12:309-321.

McDonough SI, Cseresnyes Z, Schneider MF (2000) Origin sites of calcium release and calcium oscillations in frog sympathetic neurons. J Neurosci 20:9059-9070.

Medana IM, Gallimore A, Oxenius A, Martinic MM, Wekerle H, Neumann H (2000) MHC class I-restricted killing of neurons by virus-specific CD8+ T lymphocytes is effected through the Fas/FasL, but not the perforin pathway. Eur J Immunol 30:3623-3633.

Meyer R, Weissert R, Diem R, Storck MK, de Graaf KL, Kramer B, Bähr M (2001) Acute neuronal apoptosis in a rat model of multiple sclerosis. J Neurosci 21:6214-6220.

Miller MJ, Wei SH, Parker I, Cahalan MD (2002) Two-photon imaging of lymphocyte motility and antigen response in intact lymph node. Science 296:1869-1873.

Misgeld U, Frotscher M (1982) Dependence of the viability of neurons in hippocampal slices on oxygen supply. Brain Res Bull 8:95-100.

Newman TA, Woolley ST, Hughes PM, Sibson NR, Anthony DC, Perry VH (2001) T-cell- and macrophage-mediated axon damage in the absence of a CNS-specific immune response: involvement of metalloproteinases. Brain 124:2203-2214.

Nicotera P, Orrenius S (1998) The role of calcium in apoptosis. Cell Calcium 23:173-180.

Peterson JW, Bo L, Mork S, Chang A, Trapp BD (2001) Transected neurites, apoptotic neurons, and reduced inflammation in cortical multiple sclerosis lesions. Ann Neurol 50:389-400.

Pitt W, Werner P, Raine CS (2000) Glutamate excitotoxicity in a model of multiple sclerosis. Nat Med 6:67-70.

Raine CS (1997) The Norton lecture: a review of the oligodendrocyte in the multiple sclerosis lesion. J Neuroimmunol 77:135-152.

Selmaj K, Raine CS (1988) Tumor necrosis factor mediates myelin damage in organotypic cultures of nervous tissue. Ann NY Acad Sci 540:568-570.

Smith T, Groom A, Zhu B, Turski L (2000) Autoimmune encephalomyelitis ameliorated by AMPA antagonists. Nat Med 6:62-66.

Steinman L (2001) Multiple sclerosis: a two-stage disease. Nat Immunol 9:762-764.

Trapp BD, Peterson J, Ransohoff RM, Rudick RA, Mork S, Bo L (1998) Axonal transection in the lesions of multiple sclerosis. N Engl J Med 338:278-285.

Yu SP, Canzoniero LM, Choi DW (2001) Ion homeostasis and apoptosis Curr Opin Cell Biol 13:405-411. 